\title{
La Focalización en el Régimen Subsidiado de Salud: Elementos para un Balance ${ }^{1}$
}

\author{
Óscar Fresneda Bautista
}

Sociólogo. M. Sc. Economía. Centro de Investigaciones para el Desarrollo- CID. Universidad Nacional de Colombia. E-mail: fresneda@tutopia.com imica@hotmail.com

\section{RESUMEN}

Apoyado en los resultados del proyecto "Evaluación de los Procesos del Régimen subsidiado en Salud", se presenta una reflexión sobre el sistema de selección de beneficiarios-Sisben, como herramienta para afiliar población al régimen subsidiado en salud. Se documentan y analizan las múltiples interpretaciones que se han dado al Sisben como instrumento para focalizar los servicios de salud en la población más pobre. Se le ha interpretado, entre otras acepciones, como una medida del tamaño de la pobreza, como un indicador aproximado de recursos o ingresos, o como una evaluación de satisfacción de necesidades. Se ha encontrado que de los 19 millones de pobre en 1997 menos de la mitad, 8,9, se incluyen como tales en los niveles 1 y 2 del Sisben, lo que representan un error de exclusión del 53,1 \%. Y de los 10,6 millones de personas clasificadas en estos mismos niveles, 1,6 son no pobres, con lo cual el error de inclusión es de 14,9 por ciento. Estas y otras cifras que se comentan en el texto muestran las ventajas relativas de los puntajes actuales del Sisben para excluir a los no pobres y sus grandes limitaciones para identificar a los pobres. Los errores de exclusión son mucho más graves que los de inclusión ya que significan una negación de los derechos y servicios iguales para quienes reúnen condiciones semejantes según un criterio de asignación.

Palabras Claves: Pobreza, subsidios, asignación de recursos, (fuente: DeCS, BIREME).

\section{ABSTRACT}

\section{Focusing on the subsidized health regime in Colombia}

\footnotetext{
${ }^{1}$ Los contenidos del artículo, aunque sólo comprometen al autor, se basan en los resultados y conclusiones que sobre el tema de la identificación y selección de beneficiarios ha obtenido el Proyecto Evaluación de los procesos del Régimen Subsidiado en Salud, realizado por el Centro de Investigaciones para el Desarrollo-CID, de la Universidad Nacional de Colombia, mediante contrato con el Ministerio de Salud de Colombia (Programa de Apoyo a la Reforma de Salud) y con financiación del Banco Interamericano de Desarrollo-BID. Los informes de investigación sobre éste y los restantes temas tratados en el Proyecto se encuentran publicados en tres tomos de la colección La seguridad Social en la encrucijada, 2002, Universidad Nacional, Facultad de Ciencias Económicas, CID; Ministerio de Salud, Programa de Apoyo a la Reforma. La dirección del Proyecto estuvo a cargo de Óscar Rodríguez Salazar.
} 
Based on the results of the project "Evaluation of the Processes of the Subsidized health regime" in Colombia, a reflection is presented about the beneficiary selection system-Sisben as a tool to affiliate people to the subsidized health regime. The multiple interpretations which have been given to the Sisben as an instrument to focalize the health services in the poorest populations, are documented and analyzed. This has been interpreted, amongst others, as a measure of the magnitude of poverty, as an approximate indicator of resources or income, or as an evaluation of fulfillment of needs. It was found that amongst the 19 million of poor people living in Colombia in 1997, less than half of them, 8,9 million, have been included in levels 1 and 2 of Sisben, which represents an exclusion error of 53,1\%. Of the 10,6 million persons classified in these levels, 1,6 \% are not poor, giving an inclusion error of $14.9 \%$. The exclusion errors are much more serious then the inclusion ones, because they mean a denial of equal rights and services for all those who are in similar conditions, according to the criteria for assignation of subsidies.

Key Words: Poverty, government subsidies, resource allocation (source: $M e S H, N L M$ ).

$\mathrm{E}$ ste artículo contiene algunos elementos de evaluación sobre los instrumentos, procesos y resultados de la forma como se ha llevado a cabo la selección de beneficiarios en el régimen subsidiado de salud en Colombia. Aborda el examen de las características técnicas e institucionales del Sisben (Sistema de Selección de Beneficiarios) en tres aspectos:

- La capacidad técnica del índice que se ha aplicado para la identificación de los beneficiarios de los subsidios de salud (índice Sisben).

- La forma como se ha venido llevando a cabo la implementación del Sisben, en tanto programa de los municipios, y la calidad de la información de que dispone.

- Los resultados obtenidos de la utilización del Sisben en la focalización de subsidios y en la extensión del aseguramiento en salud de los pobres y en el acceso a los servicios por parte de ellos.

Al tratar estos temas se considera que la evaluación del Sisben trasciende la consideración de los logros para llevar a cabo una selección adecuada, e incluye igualmente examinar, dentro de un contexto institucional, tanto los procesos a través de los cuales se aplica, como los cambios en el comportamiento de distintos sectores de la población en lo económico, social y cultural ante los incentivos promovidos por la focalización y ante la forma como se lleva a cabo.

En la primera parte del artículo se hace un recuento de los contenidos de la reforma que creó el Sistema General de Seguridad Social en Salud-SGSSS, y de las etapas de aplicación del Sisben. En la segunda se tratan las características técnicas del índice Sisben y su capacidad para seleccionar a la población sin capacidad de pago. La tercera ilustra algunos de los rasgos que caracterizan el estado de aplicación del Sisben y los problemas de su instrumentación. En la cuarta parte se hace un balance del grado de "focalización" lograda en el régimen subsidiado, de los resultados en la cobertura del aseguramiento de los pobres con la aplicación de la Ley 100 y de las inequidades que ha promovido en el acceso a los servicios de salud. La quinta y última sección contiene algunas conclusiones y recomendaciones. 
Aunque el Sisben es utilizado para la identificar a los beneficiarios de programas sociales de diversa índole (educación, vivienda, poblaciones jóvenes, mujeres cabeza de familia, tercera edad, etcétera), el artículo se centra en aspectos relacionados con el régimen subsidiado de salud, cuya aplicación en los de municipios del país ha sido más amplia y continua. Las secciones segunda y tercera hacen referencia, no obstante, a asuntos generales, técnicos, organizativos y operativos del Sisben.

\section{EL SGSSS Y EL RÉGIMEN SUBSIDIADO}

La reforma al sistema de salud a través de la Ley 100

El régimen subsidiado de salud es pieza clave de la reforma del sistema de salud aprobada por la Ley 100 de 1993. Ésta definió el marco normativo y el entorno institucional para la aplicación del derecho irrenunciable a la seguridad social sancionado por la Constitución de 1991, como un servicio público obligatorio que se ejerce bajo la dirección y el control del Estado. Y buscó responder a los problemas de inequidad, ineficiencia y mala calidad en la prestación de los servicios de salud. Para ello introdujo una nueva asignación en las funciones y responsabilidades de los agentes y definió los campos de intervención del Estado para garantizar los principios constitucionales, y ejercer las responsabilidades de dirección, coordinación, vigilancia, regulación y control que le corresponde cumplir.

Del lado de la demanda los cambios más sobresalientes introducidos por la Ley 100 son:

- Se convierte en obligatoria la afiliación al sistema de seguridad social en salud. La Ley establece que en el año 2000 se debería llegar a la afiliación universal de la población del país y crea mecanismos para la progresiva ampliación de la cobertura del aseguramiento. Sin embargo, la Ley 715 de 2001 aplaza indefinidamente esta aspiración, al dictaminar que, a partir de 2004, "el Sistema de Seguridad Social en Salud deberá recuperar la meta de lograr aseguramiento universal de la población.”

- $\quad$ Se establecen dos tipos de afiliados al Sistema de Seguridad Social en Salud: los afiliados al régimen contributivo y los afiliados al régimen subsidiado. Como medida de transición, se les asigna a cada uno de ellos un cubrimiento distinto en los riesgos y los servicios a que se tiene derecho. El régimen contributivo, considera un plan básico de atención para las personas con capacidad de pago (Plan Obligatorio de Salud-POS), las cuales deben hacer aportes correspondientes al $12 \%$ de sus ingresos. El subsidiado es financiado con fondos públicos y comprende un plan de aseguramiento de inferior cobertura en los servicios, para personas sin capacidad de pago. El acceso a los servicios no cubiertos por el régimen subsidiado requiere de aportes de los beneficiarios. Para la fase de transición se crea igualmente la categoría de los "vinculados" que comprende las personas sin capacidad de pago que, en tanto sean afiliadas al régimen subsidiado, seguirán recibiendo subsidios por la vía de la oferta, a través de servicios prestados por la red pública de salud. 
- $\quad$ Se crea un sistema de subsidios cruzados, mediante el cual los afiliados al régimen contributivo con mayores ingresos aportan una contribución del 1\% de los mismos para el régimen subsidiado, a través del Fondo de Solidaridad y Garantías.

- $\quad$ Tanto en el régimen contributivo, como en el subsidiado los usuarios quedan con la posibilidad de seleccionar su afiliación entre distintas entidades aseguradoras (Empresas Promotoras de Salud-EPS, para la población con capacidad de pago, y Administradoras del Régimen Subsidiado-ARS).

Desde la oferta son notables los cambios siguientes instaurados por la Ley:

- $\quad$ Se acaba el monopolio público en la afiliación y la prestación de servicios de salud para la seguridad social.

- $\quad$ Las funciones de afiliación, recaudo y manejo del aseguramiento contributivo queda a cargo de las EPS.

- Los municipios administran el régimen subsidiado seleccionando los beneficiarios, a través del Sisben, y contratando con las ARS la afiliación y prestación de servicios. La mayor parte de la financiación del régimen subsidiado se hace mediante transferencias de inversión social que hace la Nación directamente, o a través de los Departamentos, a los municipios, y con los recursos del Fondo de Solidaridad y Garantías.

- $\quad$ Tanto las EPS como las ARS contratan la prestación de los servicios contenidos en el POS de los dos regímenes, a través de redes de Instituciones Prestadoras de Servicios-IPS.

- $\quad$ Para el financiamiento de los hospitales públicos se reemplaza progresivamente el presupuesto tradicional de recursos de oferta, por un sistema de pago que toma en cuenta el tipo y cantidad de servicios prestados. Los hospitales se transforman en Empresas Sociales del Estado-ESE, con funcionamiento descentralizado, patrimonio propio, autonomía administrativa y recursos provenientes de la venta de servicios.

- $\quad$ Los Programas de Salud Pública son realizados con fondos públicos y ejecutados por las administraciones departamentales y municipales.

- Las funciones de dirección, coordinación y regulación del Sistema de Seguridad Social en Salud, queda a cargo del Ministerio de Salud y el Consejo Nacional de Seguridad Social en Salud, y las de vigilancia y control en manos de la Superintendencia Nacional de Salud. La Ley establece, en el marco de la descentralización administrativa, las competencias de las autoridades territoriales, y crea mecanismos para que las comunidades participen en las entidades que conforman el sistema y realicen labores de vigilancia.

La población beneficiaria del régimen subsidiado

La Ley 100 fija como objetivo general del Sistema de Seguridad Social en Salud "regular el servicio público esencial de salud y crear condiciones de acceso de toda la población al servicio en todos los niveles de atención.” Asimismo, establece que el sistema debe funcionar conforme a los principios de eficiencia, universalidad, solidaridad e integralidad. Entre sus directrices consigan la equidad definida como la provisión gradual de servicios de igual calidad para toda la población, 
independientemente de su capacidad de pago y de su riesgo de contraer enfermedades. Desde esa perspectiva determina que "para evitar la discriminación por capacidad de pago o riesgo, el Sistema ofrecerá financiamiento especial para aquella población más pobre y vulnerable, así como los mecanismos para evitar la selección adversa.”

Sobre esta base, la Ley 100 define que los destinatarios del régimen subsidiado son las personas pertenecientes a núcleos familiares que no cuentan con la capacidad de pago para estar afiliadas al régimen contributivo, y que será subsidiada "la población más pobre y vulnerable del país."

Se combinan así dos criterios para determinar los beneficiarios: la carencia de ingresos, y la vulnerabilidad ante los riesgos que afectan la salud. El primero corresponde principalmente con el objetivo de disminución de la pobreza, como falta de ingresos. El segundo, con el propósito de garantizar que determinados grupos, con desventajas en capacidades específicas para tener una vida sana, accedan a los servicios.

La Ley asigna, como función del Consejo Superior de Seguridad Social en Salud, la definición de criterios generales de selección de beneficiarios del régimen subsidiado, que deberán ser aplicados por los departamentos y municipios, "dando la debida prioridad a los grupos pobres y vulnerables.”

En los dos criterios de focalización subyacen enfoques no coincidentes, con implicaciones distintas en cuanto a los incentivos que promueven, los costos sociales que generan y el tipo de información que requieren para su aplicación. El de la falta de capacidad de pago, responde a una tendencia mundial y su aplicación conduce, como expresa Sen, a un procedimiento de selección que "puede tener considerables costos administrativos -consistentes en el gasto de recursos y retrasos burocráticos- y entrañar la pérdida de intimidad y de autonomía individual que implican la necesidad de revelar una gran cantidad de información y el correspondiente programa de investigación y seguimiento. A estos costes hay que sumar, además, los costes sociales del poder asimétrico de que disfrutan los potentados de la burocracia frente a los suplicantes solicitantes. Y por si esto fuera poco, en este caso existen mayores posibilidades de que haya corrupción, ya que en un sistema de ayuda condicionada los potentados adquieren la potestad de conceder prestaciones por cuya concesión los beneficiarios pueden no estar dispuestos a pagar”(1,2). Hay además otras posibles distorsiones promovidas por los intentos de lograr una selección adecuada de los beneficiarios de programas focalizados a través de los ingresos, que a su vez, promueven incentivos y desutilidades que inciden en el bienestar de las personas: distorsión de la información, distorsión de incentivos, desutilidad y estigma, viabilidad política y calidad.

Por su parte, la asignación de subsidios en términos de privación de capacidades “es un criterio de las desventajas más importante que la renta baja, ya que la renta sólo es importante desde el punto de vista instrumental, y su valor derivado de muchas circunstancias sociales y económicas.” Además, en tanto toma en cuenta factores causales estructurales de las personas (incapacidades físicas, edad avanzada, sexo, por ejemplo), su aplicación es más difícil de manipular, requiere de 
información más directa y simple de comprobar, y propicia en menor nivel incentivos indeseables (1).

La distribución de subsidios en función de la privación de capacidades no da cuenta, sin embargo, de todos los objetivos que se pueden valorar como importantes para determinados programas sociales. Sen considera que "la decisión de proporcionar ayuda en función de la falta de capacidades y no de la falta de renta no evita por sí sola la necesidad de juzgar la pobreza económica de los posibles beneficiarios, ya que también hay otra cuestión, y es cómo debe distribuirse la ayuda pública. En concreto, existe la posibilidad de cobrar los servicios públicos en función de la capacidad de pago, lo que obliga de nuevo a introducir la necesidad de averiguar la renta del posible beneficiario". Y añade que, cuando el objetivo de un programa "es proporcionar un servicio gratuito a los pobres pero no a los que pueden pagarlo, hay que comprobar las circunstancias económicas de la persona” (1).

La adopción de uno u otro enfoque ha dado lugar a salidas institucionales particulares en el campo de los sistemas de salud. "La formula europea de proporcionar asistencia médica en función de la falta de capacidades sin tener en cuenta los ingresos ha tendido a adoptar la forma de un servicio sanitario nacional general abierto a todos los que necesiten asistencia médica. Ese sistema facilita la tarea de obtener información, pero no resuelve el problema de la división entre los ricos y los pobres." Hay otras salidas intermedias que han tratado de compatibilizar los enfoques de privación de capacidades y falta de capacidad de pago. "La fórmula americana de Medicaid tiene por objeto proporcionar ayuda en función de la falta de capacidades y de los ingresos (en un nivel más modesto) y ha de hacer frente a los dos problemas de información” (1).

El modelo institucional instaurado por la Ley 100 se dirige a lograr no sólo una mayor y mejor provisión de servicios sino también un aseguramiento universal, en el que cada cual contribuya de acuerdo con sus posibilidades y reciba una atención que corresponda con sus necesidades. Cuando este objetivo se haya logrado, todos estarán protegidos frente a riesgos, los cuales varían de acuerdo con características individuales y de los entornos familiares, sociales y ambientales, y que tienen costos diferentes para ser cubiertos. Ya que el valor del aseguramiento depende de esas características, el objetivo es lograr una igualdad en las capacidades, dando un trato diferente a los diferentes. Mediante contribuciones acordes con las posibilidades económicas de las personas, se busca completar la meta de equidad y hacer práctico el principio de solidaridad, mediante una acción colectiva que tienda a contrarrestar las desventajas de los más vulnerables.

Con este objetivo, una vez lograda la cobertura universal y única de aseguramiento, se requiere principalmente un instrumento que permita determinar los aportes con base en la capacidad económica. Durante la fase de transición hacia esta meta, que de acuerdo con las previsiones de costos puede demorar varias décadas, sería necesario adoptar un enfoque intermedio que contrarreste las desventajas de los más vulnerables a los riesgos de salud dándoles prelación en el aseguramiento, al mismo tiempo que se controlan la asignación de subsidios y los aportes de acuerdo con la capacidad de pago. De esta forma se crean, además, condiciones para la unificación ambos regímenes con el fin de eliminar la segmentación existente. Esa perspectiva implica, sin 
embargo, afrontar las desventajas de asignación de tarifas y definición de beneficiarios de subsidios con base en el ingreso, tratando de adoptar mecanismos que las minimicen.

\section{La aplicación del Sisben}

En el momento en que se aprobó la Ley 100 ya se había iniciado el diseño técnico de Sisben, por parte de la Misión Social del Departamento Nacional de Planeación, como un instrumento genérico para la focalización de programas sociales, dentro del contexto de las reformas sociales que tuvieron lugar en Colombia y América Latina y que privilegiaban los subsidios a la demanda. La Constitución de 1991 había sentado las bases jurídicas para llevarlas a cabo y la Ley 60 de 1993 había concretado sus alcances en la perspectiva de la descentralización administrativa especialmente en los campos de la educación y la salud.

Para agilizar la puesta en marcha del régimen subsidiado, en un comienzo, se resolvió la selección de beneficiarios mediante criterios pragmáticos, autorizando la utilización de mecanismos como listados censales en los municipios con altos índices de Necesidades Básicas InsatisfechasNBI, y la estratificación socioeconómica existente para el cobro de servicios públicos domiciliarios. En 1994 se publican los instructivos y cartillas para la aplicación y organización del Sisben en los municipios y se inicia un programa de apoyo para su instrumentación, y en 1995 se convierte en obligatorio su uso para los municipios de mayor tamaño poblacional y desarrollo institucional, bajo la responsabilidad de los alcaldes. Con el Acuerdo 77 de 1997 del Consejo Superior de Seguridad Social en Salud, la obligación se extiende a todos los municipios del país. Este Acuerdo reglamenta, además, procedimientos para la vigilancia y control del Sisben (informes al Consejo Territorial de Seguridad Social en Salud, verificación por parte de las Direcciones Locales y Distritales de Salud, Personerías Municipales, Veedurías Comunitarias, Mesas de Solidaridad) y fija criterios para hacer nuevas afiliaciones, privilegiando el mantenimiento en la afiliación de los ya incluidos.

El Acuerdo establece que, para la asignación de los cupos adicionales disponibles, teniendo en cuenta los recursos municipales, las alcaldías deberán elaborar una lista de potenciales afiliados. Ésta deberá estar incluir a población perteneciente a los niveles 1 y 2 del índice Sisben, "teniendo en cuenta el siguiente orden: 1. Población del área rural; 2. Población indígena; 3. Población urbana. En cada uno de los grupos de población se priorizarán los potenciales afiliados así: 1. Mujeres en estado de embarazo y niños menores de cinco años; 2. Población con limitaciones físicas, síquicas y sensoriales; 3. Población de la tercera edad; 4. Mujeres cabeza de familia; 5. Demás población pobre y vulnerable.” Con base en esta agrupación la selección se llevará a cabo teniendo en cuenta el ordenamiento provisto por el puntaje del índice Sisben, hasta que los cupos vacantes sean provistos.

Este procedimiento, busca combinar los dos enfoques de selección, bajo el supuesto de que el índice Sisben identifica a los pobres por ingresos, dando prioridad a ciertos grupos vulnerables, dentro del amplio grupo de quienes carecen de capacidad de pago. 
El documento Conpes 55 de 2001 define criterios generales para modificar el índice Sisben, actualizar la información de las encuestas, mejorar algunos procesos operativos y mecanismos de control de calidad sobre la información. La aplicación de los lineamientos definidos se propone implantar un "nuevo instrumento de focalización”.

La Ley 715 de 2001, a través de la cual se modifica la Ley 60, otorga al Conpes la exclusiva competencia de definir el instrumento de focalización a ser utilizado en el régimen subsidiado, y establece que su información debe ser actualizada cada tres años (artículos 48 y 94). Otorga al Sisben la función adicional de determinar la "población pobre por atender", que corresponde con los vinculados de los municipios: quienes carecen de capacidad de pago y no están afiliados al régimen subsidiado. Del tamaño de esta población dependen las trasferencias nacionales a los municipios para salud.

El acuerdo 244 de 2003 del Consejo Nacional de Seguridad Social en Salud "determina los criterios para identificar, seleccionar y priorizar a los potenciales beneficiarios de los subsidios, el procedimiento de afiliación de beneficiarios, la operación regional de las Administradoras de Régimen Subsidiado y el proceso de contratación del aseguramiento.” Sustituye una multiplicidad de normas dispersas sobre el régimen subsidiado y es el marco reglamentario básico para la operación del régimen subsidiado.

En 2003 se inició, por parte del Departamento Nacional de Planeación, el programa de aplicación del llamado "nuevo" Sisben que desarrolla las orientaciones del documento Conpes 55 en los municipios.

\section{El Sisben como instrumento de focalización}

Características técnicas del índice Sisben. El índice Sisben aplicado hasta el año 2002 se construyó a partir de técnicas estadísticas con las cuales se asigna un valor a categorías de variables cualitativas que expresan las condiciones de vida de los hogares. Con los valores dados a las categorías se construyeron índices parciales con el método del análisis de componentes principales, sobre cuatro grupos temáticos: calidad de la vivienda y equipamiento doméstico; condiciones demográficas; ingreso y ocupación; educación y seguridad social. Utilizando estos índices, y nuevamente el método de componentes principales, se elabora un índice global, cuyos puntajes se transforman para que su rango se encuentre entre cero y $100(3,4)$.

El diseño del índice y la definición de los niveles de sus puntajes se realizó a partir de los resultados de una encuesta de hogares realizada en 1993 (Casen, Departamento Nacional de Planeación). Para la identificación de beneficiarios de programas sociales, la información sobre las variables incluidas en el índice se recolecta a través de un formulario especial y es procesada por medio de un software que calcula los puntajes, permite administrar las bases de datos consolidadas del municipio y generar informes. Los municipios efectúan el acopio de la información ya sea por medio de operativos masivos en zonas definidas localmente (encuestas "por barrido") o a solicitud de las familias interesadas (encuestas "a la demanda”). 
Los puntajes del índice se agruparon en seis niveles, definidos según la probabilidad de que expresen situaciones de pobreza, o rangos de ingreso por persona de las familias. Los dos primeros niveles están asociados con grados de intensidad de la pobreza, de acuerdo con el uso simultáneo de los métodos de ingresos (línea de pobreza) y necesidades básicas insatisfechas (NBI). El nivel $1^{\circ}$ está correlacionado con circunstancias de las familias en pobreza "extrema": con dos o más indicadores de NBI ("miseria”) o con ingresos inferiores a la línea de indigencia (valor de una canasta básica de alimentos). El segundo tiende a captar las restantes características de la pobreza identificadas por los dos métodos. Y los niveles $3^{\circ}$ a $6^{\circ}$ se definen en función de rangos de ingreso de las familias.

El Acuerdo 77 estableció que las familias clasificadas en los niveles 1 y 2 pueden ser afiliadas al régimen subsidiado. Permite que también lo sean las del nivel 3 en casos excepcionales autorizados por el Consejo Nacional de Seguridad Social en Salud.

Los elementos de evaluación del índice Sisben de esta sección se refieren al aplicado hasta el año 2002. No considera el "nuevo" Sisben ya que los detalles de su metodología se han mantenido en secreto por parte del DNP, bajo la justificación de que si la población conociera las variables, ponderaciones y puntos de corte para el cálculo de los puntajes, se generarían condiciones para distorsionar las informaciones aportadas por los encuestados. Sobre este punto se volverá más adelante.

No obstante, hasta donde es de conocimiento público, la elaboración del "nuevo” índice Sisben, se ha realizado básicamente con las mismas técnicas estadísticas que el anterior y bajo las mismas restricciones de información. De esta forma, es altamente probable que, aunque haya habido mejoras y se base en una encuesta más reciente, las potencialidades del nuevo índice no sean significativamente diferentes a las del anterior. Y, es razonable suponer que el mantenimiento de los procedimientos metodológicos permite seguir interpretando el contenido del nuevo índice en la misma forma que la del "viejo".

¿ Qué mide el índice Sisben?

En su presentación técnica inicial el índice se interpretó como una medida del "tamaño" de la pobreza, en tanto permitía ordenar las familias por el nivel de la misma (2). Aunque no se hizo explicita la concepción de la pobreza adoptada queda evidente al definir los puntos de corte de los dos primeros niveles del índice, a partir de los resultados provistos por los enfoques de línea de pobreza y necesidades básicas insatisfechas. Son introducidas, así, las concepciones implícitas en esas metodologías y en su uso conjunto. El índice se convierte en una variable a partir de la cual, en forma indirecta, se podría medir la pobreza captada por los dos métodos. No era una medida alterna de la pobreza, sino una variable que permitía estimar su incidencia e identificar de manera individual a las familias pobres.

Posteriormente se han dado dos interpretaciones más amplias del índice. La primera considera que, tanto por las variables que contiene como por su forma de construcción, puede considerarse 
como un indicador aproximado de recursos o ingresos y, en un sentido más profundo, expresa la utilidad de los hogares y su grado de bienestar (5). Sobre esta base el índice podría dar solución al requerimiento de buscar un método de focalización que tome en cuenta la capacidad de pago de los hogares para la asignación de subsidios y eventualmente la fijación de tarifas.

Conforme a la segunda interpretación el índice Sisben "se aproxima a las realizaciones y capacidades" y evalúa satisfacción de necesidades y no preferencias. "Más que un índice de pobreza, el I-Sisben (índice Sisben) es un índice de estándar de vida, porque informa, de manera directa, sobre las realizaciones y las capacidades.” (6). Esta posición acepta, en general, la adecuación del índice para la asignación de subsidios bajo una concepción que busca superar la visión restringida de los ingresos. En tanto instrumento genérico el criterio de focalización no sería dar preferencia en la asignación de subsidios a quienes tengan menores capacidades en campos particulares como el de la salud, sino reducir el grado de privación y disminuir las desigualdades desde el punto de vista genérico de las capacidades en el nivel de estándar de vida. Esta posición sostiene, además, que la definición sobre cuál debe ser la población subsidiada es un asunto que decide cada gobierno o entidad a partir del ordenamiento de la población provisto por el índice, “en función de sus propósitos y de sus recursos” (6).

En el marco de los objetivos del régimen subsidiado y la definición de sus beneficiarios, en las secciones siguientes se analiza la capacidad técnica del índice Sisben para dar cuenta de los niveles de ingreso corriente e identificar de forma adecuada a la población pobre. En tanto los ingresos constituyen un elemento cuya consideración forma parte del análisis de las capacidades, por este camino se obtiene una aproximación a la pertinencia del índice como indicador de estándar de vida, bajo tal enfoque.

Para hacerlo se utiliza la información de la Encuesta Nacional de Calidad de Vida de 1997. El recurso a esta fuente tiene como ventaja que la encuesta fue realizada con procedimientos que buscaron una alta calidad en la información, incluyendo las variables consideradas en el índice Sisben y el ingreso.

Estas evaluaciones sólo se refieren a la capacidad del instrumento en condiciones de información controlada y confiable, sin tomar en cuenta los sesgos atribuibles a la obtención del índice a través de las encuestas aplicadas por las alcaldías. Los ejercicios pueden equiparase a pruebas de laboratorio, donde se controlan los efectos de distorsiones de información debidos a condiciones operativas y a los incentivos para ser acreedor de un subsidio.

El índice Sisben como índice de ingresos

La asociación entre el puntaje Sisben y los ingresos corrientes de los hogares puede apreciarse a través de los resultados de modelos univariados de regresión entre el logaritmo del ingreso per cápita, como variable dependiente, y los puntajes del índice Sisben como independiente, para las zonas urbana y rural y para Bogotá. 
Los resultados de la aplicación de los modelos muestran una correlación positiva entre las dos variables. El coeficiente de determinación obtenido para la zona urbana (cabeceras muncipales) y para Bogotá es 0.52, y para la rural 0.27 (resto de la población de los municipios), como se indica en la Tabla 1.

La magnitud de estos coeficientes para la zona urbana y para Bogotá puede considerarse relativamente alta, teniendo en cuenta que se trata de series transversales. Sin embargo, las estimaciones puntuales del ingreso para hogares determinados a partir del puntaje Sisben y utilizando los parámetros de la regresión, daría lugar a imprecisiones considerables, como lo ilustran las Figuras 1 y 2, en los cuales se aprecia la diferencia entre los valores estimados con los modelos (la recta de los gráficos) y los valores observados (la nube de puntos en las figuras).

Además es notoria la baja correspondencia entre los ordenamientos que proveen el índice Sisben, de una parte, y el ingreso per cápita, de otra, a través de la clasificación de hogares por quintiles de las dos variables. Con este procedimiento se concluye que sólo el $46 \%$ de las personas en las áreas urbanas queda clasificado en el mismo rango según los dos criterios de ordenamiento, y, en las rurales, el porcentaje de coincidencia es de 33. Otra medida de la asociación entre el ordenamiento de los puntajes del índice Sisben y el ingreso per cápita de los hogares es el coeficiente de correlación de Spearman. En las áreas urbanas su valor es de 0.784 y en las rurales de 0.519 .

Tabla 1. Resultados de los ejercicios de regresión del logaritmo del ingreso per cápita en función del índice Sisben, $1997^{(1)}$

\begin{tabular}{lccc}
\hline Nivel geográfico & $\begin{array}{c}\mathrm{R}^{2} \text { Coeficiente de } \\
\text { determinación } \\
\text { Ajustado }\end{array}$ & Intercepto & $\begin{array}{c}\text { Coeficiente del } \\
\text { puntaje Sisben }\end{array}$ \\
\hline Total nacional & 0.4505 & 9.619581 & 0.039828 \\
Zona urbana & 0.5283 & 8.134986 & 0.062224 \\
Zona rural & 0.2695 & 9.806644 & 0.039953 \\
Bogotá, área metropolitana & 0.5238 & 7.506767 & 0.071984 \\
\hline \multicolumn{2}{r}{ Fuente: CID, Universidad Nacional de Colombia, con base en los archivos de la Encuesta Nacional } \\
de Condiciones de Vida (DANE), conformados por la Misión Social del DNP. \\
(1) Todos los coeficientes son significativos al nivel de 0.005.
\end{tabular}

Los resultados de estas pruebas expresan un grado de asociación que puede considerarse satisfactorio para ciertos análisis globales de tendencias, pero que es insuficiente para determinar con precisión los niveles de ingresos de las familias en particular, en la perspectiva de asignación de subsidios o fijación de tarifas, tomando en cuenta la capacidad de pago.

¿Identifica el Sisben a los pobres?

La capacidad de los niveles del índice para identificar a los pobres se evalua a través de las frecuencias cruzadas de la población clasificada según estos niveles y por su condición de pobreza. Sobre esta base es posible calcular los errores de inclusión (tipo 1, la proporción de no pobres 
identificados como pobres) y de exclusión (tipo 2, la proporción de pobres que son identificados como no pobres). La Tabla 2 contiene los resultados.

De los 19 millones de pobres en 1997 menos de la mitad, 8900 000, son clasificados como tales en los niveles 1 y 2 del Sisben, por lo general utilizados para identificar a los núcleos familiares elegibles para ser afiliados al régimen subsidiado. De esta forma el error de exclusión es de 53,1 \%. $\mathrm{Y}$ de las 10550000 personas clasificadas en estos mismos niveles, 1550000 son no pobres, con lo cual el error de inclusión es de 14,9\%.

Figura 1. Ingreso per cápita de los hogares urbanos (logaritmo) y puntaje Sisben, 1997

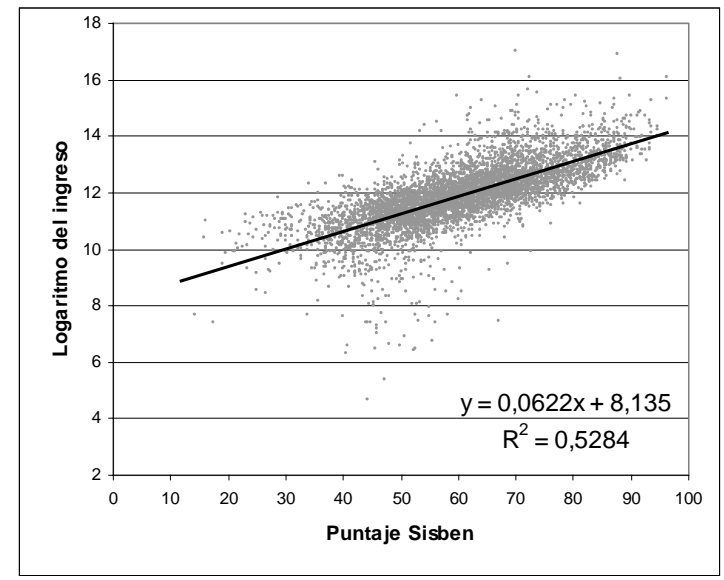

Fuente: Encuesta Nacional de Calidad de Vida, 1997.

Figura 2. Ingreso per cápita de los hogares rurales (logaritmo) y puntaje Sisben, 1997

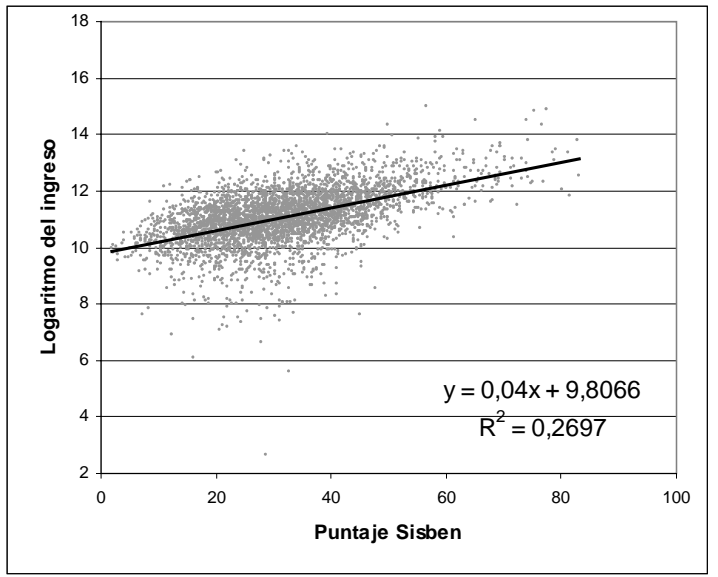

Fuente: Encuesta Nacional de Calidad de Vida, 1997. 
Con un mecanismo totalmente aleatorio, la probabilidad de que una persona pobre fuera escogida como beneficiaria del régimen subsidiado sería igual a la tasa de incidencia de la pobreza: 0.476. Con la aplicación de la metodología del Sisben esa probabilidad sería algo menor: 0.469 (la proporción de pobres clasificados en los niveles 1 y 2). Bajo esta consideración, la "eficiencia” del índice es negativa para identificar a los pobres: se lograría un mejor resultado con un método de azar, a través de utilizar una moneda, por ejemplo.

En las zonas urbanas el error de inclusión es más bajo, 6,2 \%, pero el de exclusión es más elevado, 65,2 \%. Y en las rurales alcanza valores más altos el error de inclusión, 21,3 \%, mientras que el de exclusión es inferior, 32,1\%.

Tabla 2. Población por niveles del Sisben y condición de pobreza (bajo las líneas de pobreza e indigencia). Errores tipo 1 y 2 para identificar los pobres a través del índice Sisben Total Nacional, 1997

\begin{tabular}{|c|c|c|c|c|c|c|c|}
\hline \multirow{2}{*}{$\begin{array}{c}\text { Condición de } \\
\text { pobreza }\end{array}$} & \multicolumn{7}{|c|}{ Niveles del Sisben } \\
\hline & Total & 1 & 2 & 3 & 4 a 6 & 1 y 2 & 3 a 6 \\
\hline Total & 39842424 & 2789919 & 7658449 & 11214940 & 18179116 & 10448368 & 29394056 \\
\hline No pobre & 20887141 & 226967 & 1327268 & 3931668 & 15401238 & 1554235 & 19332906 \\
\hline Total pobre & 18955283 & 2562952 & 6331181 & 7283272 & 2777878 & 8894133 & 10061150 \\
\hline Pobre no indigente & 11823751 & 1095886 & 3250137 & 5025366 & 2452362 & 4346023 & 7477728 \\
\hline Pobre indigente & 7131532 & 1467066 & 3081044 & 2257906 & 325516 & 4548110 & 2583422 \\
\hline \multicolumn{8}{|c|}{ Porcentajes verticales: errores tipo 1 (de inclusión) 14,9\% de los no pobres } \\
\hline & Total & 1 & 2 & 3 & 4 a 6 & $1 \mathrm{y} 2$ & 3 a 6 \\
\hline Total & 100,0 & 100,0 & 100,0 & 100,0 & 100,0 & 100,0 & 100,0 \\
\hline No pobre & 52,4 & 8,1 & 17,3 & 35,1 & 84,7 & 14,9 & 65,8 \\
\hline Total pobre & 47,6 & 91,9 & 82,7 & 64,9 & 15,3 & 85,1 & 34,2 \\
\hline Pobre no indigente & 29,7 & 39,3 & 42,4 & 44,8 & 13,5 & 41,6 & 25,4 \\
\hline Pobre indigente & 17,9 & 52,6 & 40,2 & 20,1 & 1,8 & 43,5 & 8,8 \\
\hline \multicolumn{8}{|c|}{ Porcentajes Horizontales: errores tipo 2 (de exclusión) 53,1\% de los pobres } \\
\hline & Total & 1 & 2 & 3 & 4 a 6 & 1 y 2 & 3 a 6 \\
\hline Total & 100,0 & 7,0 & 19,2 & 28,1 & 45,6 & 26,2 & 73,8 \\
\hline No pobre & 100,0 & 1,1 & 6,4 & 18,8 & 73,7 & 7,4 & 92,6 \\
\hline Total pobre & 100,0 & 13,5 & 33,4 & 38,4 & 14,7 & 46,9 & 53,1 \\
\hline Pobre no indigente & 100,0 & 9,3 & 27,5 & 42,5 & 20,7 & 36,8 & 63,2 \\
\hline Pobre indigente & 100,0 & 20,6 & 43,2 & 31,7 & 4,6 & 63,8 & 36,2 \\
\hline
\end{tabular}

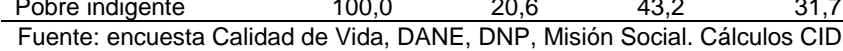

Si se aceptara que las personas clasificadas en el nivel 3 del Sisben fueran consideradas como beneficiarias, el error relativo de inclusión aumentaría en más de 10 puntos porcentuales, de 14,9 a 25,3 \%. Y el número de no pobres (error absoluto de inclusión) llegaría a casi 5 millones y medio de personas, valor que representa casi dos terceras partes de los inscritos al régimen subsidiado, en ese momento. Tal aumento en el error absoluto de inclusión, sería el costo de disminuir el error de exclusión de 53,1 \% a 14,7\%.

El cálculo de los errores de inclusión y exclusión, tomando como punto de referencia la población clasificada como pobre por el método que integra los enfoques de línea de pobreza y necesidades básicas insatisfechas-MMIP lleva a concluir que, desde esta perspectiva, aunque disminuyen de modo notable los errores de inclusión (a 5,6 \% en el total nacional, a 3,3 \% en las zonas urbanas y a 7,5 \% en las rurales) los errores de exclusión se mantienen: 50,7 \% para el conjunto del país, $62,7 \%$ en las áreas urbanas y 31,9 \% en las rurales. 
Estas cifras muestran las ventajas relativas de los puntajes actuales del Sisben para excluir a los no pobres, y sus grandes limitaciones para identificar a los pobres. Como se sabe, en la asignación de ayudas a los pobres, los errores de exclusión son mucho más graves que los de inclusión. Significan, en la práctica, una negación de derechos y servicios iguales para quienes tienen semejantes condiciones según un criterio de asignación.

\section{La implementación del Sisben}

Al establecerse como obligatoria la aplicación de las encuestas Sisben para recibir las transferencias nacionales del régimen subsidiado, dicho sistema se constituyó en un programa permanente en todos los municipios del país. A su cargo quedó una amplia y compleja gama de funciones que comprende el diseño y ejecución de las encuestas, la actualización y administración de los archivos, y la atención permanente a los usuarios institucionales y a la población.

La aplicación de las encuestas del Sisben, en áreas geográficas con bajos niveles de vida, durante la primera etapa del régimen subsidiado solucionó muchos problemas prácticos. A través suyo se pudo hacer una rápida y masiva afiliación con procedimientos estándar que controlaron la arbitrariedad en la asignación de subsidios y la influencia de preferencias basadas en consideraciones partidistas o electorales. A partir de entonces se han realizado, sin normas, controles, ni programas de apoyo generales, acciones tendientes a completar la cobertura, a actualizar la información y a responder a requerimientos de ampliación de la afiliación del régimen subsidiado o proveer información para la selección de usuarios subsidiados de otros proyectos sociales.

En esta sección se ilustran algunos resultados del Sisben, como programa municipal, en relación con la cobertura, actualización y calidad de su información con base en información relativa al año 2000. Se proveen, de esta forma los rasgos de una situación que afecta el grado de precisión de la focalización, en términos de la magnitud de los errores prácticos de inclusión y exclusión. Son examinados de igual forma aspectos relacionados: organización y forma de operación del programa.

Con el programa de aplicación del "nuevo" Sisben en el 2003, es de esperar que se produzca una actualización de la información provista por las encuestas y una mejora en su calidad. Lo que es más incierto es su efecto sobre la cobertura y sobre el establecimiento de mecanismos institucionales que garanticen mantener actualizada la información y extender la cobertura. El programa se basa en la información del "viejo" Sisben para definir las áreas prioritarias donde se aplicaría la nueva encuesta, con lo cual tendería a excluir a poblaciones no cubiertas anteriormente. $\mathrm{Y}$, de otra parte, el programa no trata los aspectos institucionales que inciden en los resultados una vez aplicadas las encuestas masivas. Sin tratarlos es previsible que en el curso de poco tiempo la calidad de la información retorne a su estado anterior.

\section{La cobertura de las encuestas del Sisben}

No hay parámetros estándar ni medidas del todo confiables para dar cuenta de la cobertura de la encuesta Sisben. Es atribución de las administraciones municipales definir si llevan a cabo las 
encuestas en el conjunto del municipio o en determinadas áreas. Generalmente la aplican al conjunto de las viviendas de los estratos socioeconómicos 1 y 2, o 1, 2 y 3 y a las familias que solicitan su aplicación.

Con el fin de tener una idea de la magnitud de la cobertura lograda hay varias vías de aproximación. Una primera medida es la proporción de personas registradas en los archivos del Sisben en relación con la población total. Aunque no existe un conteo preciso de la población registrada por los municipios en los archivos del Sisben, se estima que en 2000, lo estaban cerca de 26760000 personas, cifra que representa el 63 \% de la población nacional, 79,5\% de los habitantes de las áreas urbanas, y 56,6 \% de los de las rurales (7). Esta medida informa acerca de la magnitud de las encuestas realizadas, pero no sobre la cantidad de encuestas faltantes en relación con características relevantes para la identificación de la población pobre o vulnerable.

Una segunda aproximación consiste en interrogar a las mismas administraciones municipales sobre el porcentaje de encuestas efectuadas respecto a las que consideran que deberían haberse hecho para captar a la población pobre de los municipios. Con esta metodología se estima que el 51,6 \% de los municipios del país han logrado coberturas superiores al $90 \%$, y el 18,1\%, inferiores al $50 \%$. En situaciones intermedias, el 7,7 \% de los municipios tienen coberturas entre 50 y $69 \%$, y 19,6 \% entre 70 y 89 \%. Hay desempeños más favorables en los municipios con menor población, y más deficientes en los de tamaño intermedio (entre 50 y 100000 habitantes) y los de mayor volumen poblacional: en 77,4 \% de los municipios con menos de 10000 habitantes informaron coberturas superiores a $90 \%$; $50 \%$ entre los de 10000 a 20000 habitantes; 45,9\% entre los de 20 000 a 50 000; 4,9 \%; entre los de 50000 a 100 000; 55 \%; entre los de 100000 a 300000 y 16,7\% entre los de más de 500 000. Es notable que entre estos últimos municipios el $33 \%$ desconoce la cobertura del Sisben.

Estas medidas tienen la virtud de consultar las condiciones particulares de los municipios. No obstante, se basan, en la mayor parte de los casos, en percepciones que no se sustentan en verificaciones precisas. Los cálculos comunes de cobertura se hacen comparando el número de núcleos familiares y población registrada en los archivos del Sisben, con la población con NBI obtenidas en la mayor parte de los casos a través del censo de población de 1993, o más frecuentemente con la que habita en los estratos 1 y 2 de servicios públicos domiciliarios.

Las respuestas obtenidas de las administraciones municipales ilustran, sin embargo, sobre ventajas y desventajas particulares para el manejo del Sisben, que dependen del tamaño demográfico del municipio. En los pequeños las coberturas pueden ser mayores debido a que la operación es más fácil en los centros urbanos, y los requerimientos técnicos menos exigentes, pero los recursos son más limitados. En los intermedios y mayores, a pesar de las economías de escala que cabe esperar en la aplicación de encuestas masivas, existen circunstancias que hacen más compleja la operación: actualización cartográfica, organización y control del trabajo de campo, movilidad y crecimiento de la población. 
Una tercera forma de medición que se ha utilizado, se basa en las respuestas de los hogares cuando se les pregunta si se les ha hecho la encuesta Sisben. Por esta vía se obtuvo que el $43 \%$ de la población de los estratos 1 a 3 de las principales ciudades del país han sido "Sisbenizados" (8). La proporción es mayor en los sectores con más bajos niveles de vida: en el estrato 1 la proporción de encuestados es de $67 \%$, en el estrato 2 de $53 \%$ y en el estrato 3 de $24 \%$. En este universo la encuesta Sisben se ha hecho al 56 \% de la población con necesidades básicas insatisfechas y al 39 \% de la población con necesidades básicas satisfechas. Y ha llegado al $65 \%$ de los núcleos familiares que se ubican en los niveles 1 y 2 del Sisben, al $47 \%$ de los del nivel 3 y al $24 \%$ de los del nivel 4.

Esta forma de medir la cobertura está afectada por errores imputables al olvido de los hogares sobre las encuestas Sisben que les fueron aplicadas. Sin embargo, posiblemente recoge las percepciones acerca de lo que consideran vigente y con valor en un momento dado.

El conjunto de estas aproximaciones no da cuenta del estado global de la cobertura del Sisben para identificar a la población pobre en el año 2000. Sí ilustran deficiencias que impiden la afiliación al régimen subsidiado de sectores que aspiran a obtenerla, incrementando los errores de exclusión. Así lo considera un 10 \% de la población sin afiliación a la seguridad social en los estratos 1 a 3 de las principales ciudades, al informar que su situación se explica porque no se les había hecho la encuesta del Sisben, según la información obtenida en una encuesta de hogares y entrevistas realizadas por el Centro de Investigaciones para el Desarrollo-CID en el asño 2000.

La falta de medidas confiables sobre la cobertura de las encuestas del Sisben expresa una indefinición práctica de la población a la que están dirigidos los subsidios. Y las fallas de cobertura que, en magnitudes no concordantes, muestra la información existente, cuestionan la equidad con que son asignados, con el propósito de favorecer a los más pobres.

Los factores que inciden en los problemas de cobertura son de diversa índole. Dentro de los obstáculos que son considerados relevantes por parte de las administraciones municipales para alcanzar una cobertura total en la aplicación del Sisben, se destaca la falta de presupuesto, que abarca al $83 \%$ de los municipios con coberturas inferiores al 100 por ciento. Con frecuencias menores se señala la falta de recursos humanos, en 38,4 \% de los municipios, y técnicos, en 31,2 \% de ellos. Los problemas de orden público afectan el logro de la cobertura del Sisben en 20,6 \% de los municipios.

Actualización y calidad de la información del Sisben

Sobre el grado de actualización de la información de las encuestas del Sisben existen también sólo aproximaciones ilustrativas:

- En el año 2000, el 31 \% de las administraciones de una muestra de municipios consideraba que los archivos existentes del Sisben estaban totalmente actualizados, $36 \%$ informaban que estaban medianamente actualizados y $11 \%$ que se encontraban altamente desactualizados. La falta de instrumentos para evaluar el grado de actualización de la aplicación de las encuestas del 
Sisben se expresa en que $23 \%$ no saben o no informan sobre el asunto. El $22 \%$ de los municipios con menos de 10000 habitantes tienen el Sisben totalmente actualizado, el $51 \%$ de los de 20 mil a 50 mil habitantes y el $17 \%$ los de 500 mil y más. Durante los años 2001 y 2002 hubo muy pocas actualizaciones del Sisben, ante la perspectiva de aplicación del nuevo instrumento.

- La distribución de municipios por año de la última encuesta masiva que habían realizado muestra que ha habido procesos parciales de actualización del Sisben en los últimos años. El $37,6 \%$ de los municipios han implementado este tipo de encuestas en 1999 y 2000, y un $26 \%$ adicional lo hicieron en 1998.

- En los estratos 1 a 3 de las principales ciudades el $42 \%$ de los hogares con encuesta Sisben informa que les fue hecha en los dos últimos años,1999 y 2000, y el $65 \%$ en los tres últimos años.

- La falta de actualización del Sisben, junto a la ausencia de controles en los registros de afiliación a la seguridad social en salud, ha llevado a que cerca del 4 \% de las personas inscritas en el régimen subsidiado puedan estar duplicadas, y entre el régimen subsidiado y el contributivo existían dobles afiliaciones equivalentes a 5,9\% de los registros de beneficiarios del régimen subsidiado (8).

La dificultad que, de acuerdo con las administraciones municipales, tenía mayor extensión para llevar a cabo la actualización del Sisben es, de nuevo, la falta de presupuesto, $43 \%$ de los municipios, y la falta de recursos técnicos, 31,6 \%. A este respecto también se destaca la falta de recursos humanos, 28,7 \% y de asistencia técnica, 23,2\%.

De otra parte, una percepción sobre la calidad del Sisben se obtiene al comparar el nivel asignado por las administraciones municipales, e informado por los hogares, con el calculado a partir de la información de la encuesta a los estratos 1 a 3 de las ciudades. Con este procedimiento se infiere que el $47 \%$ de las personas que declaran estar clasificadas en los niveles 1 y 2 , pertenecen a otros niveles, de acuerdo con sus características actuales, lo que expresa que, en esa proporción, el puntaje con que han sido registrados en el Sisben está desactualizado o tiene errores en la captación de los datos. Y en ese contexto, se ha encontrado que el $44 \%$ de los afiliados al régimen subsidiado no pertenece a los niveles 1 y 2 . Aunque dentro del marco normativo hay situaciones en las cuales la afiliación de población del nivel 3 está permitida, la alta proporción de personas afiliadas al régimen subsidiado en éste y los niveles superiores es un indicador de los sesgos de información en la aplicación del Sisben.

Tales situaciones llevan a concluir que el sesgo principal de la información del Sisben para la asignación de subsidios, dentro de la metodología del instrumento, se encuentra en la inclusión de una proporción considerable de no pobres en los niveles 1 y 2. En el universo analizado casi el 50 \% de los ubicados en los puntajes que permiten el acceso al régimen subsidiado pertenecen a niveles superiores. 
Manejo político del Sisben

La administración descentralizada del régimen subsidiado de salud ha propiciado, en ciertos contextos, la incidencia de intereses partidistas y electorales en la asignación de subsidios. Es relativamente frecuente oír apreciaciones sobre la ocurrencia de estas prácticas, según las cuales se acentúan cuando coinciden los períodos de afiliación y los preelectorales. No hay, sin embargo, un registro sobre denuncias o investigaciones para precisar su alcance. A este respecto hay también sólo indicios indirectos.

Uno de ellos es la apreciación de las mismas administraciones municipales. Un $22 \%$ de ellas reconocen que ha habido entradas y salidas arbitrarias en el régimen subsidiado debido a manejos políticos en el municipio, y un $39 \%$ informan que se han presentado irregularidades respecto a la clasificación de las familias en los niveles 1 y 2. En los municipios de mayor tamaño de población es donde tiene más frecuencia este tipo de conductas, $66 \%$. Sucede en el 41,4 \% de los medianos y $36,7 \%$ de los pequeños. Una evidencia adicional proviene de la información de las administraciones departamentales, a través de las direcciones seccionales de salud que informan, en un $64 \%$, sobre la ocurrencia de este tipo de situaciones en los municipios de su jurisdicción. Existen indicios de que la aplicación del programa de aplicación del "nuevo" Sisben haya estado afectado por el ambiente de las elecciones de alcaldes en 2003. Según noticias de prensa ha habido acusaciones de manejo político del Sisben en 200 municipios (9).

Las declaraciones de la población dan cuenta igualmente del fenómeno: 10 \% de los núcleos familiares entrevistados en las principales ciudades (estratos 1 a 3 ) informan que tienen conocimiento sobre irregularidades en los procesos de afiliación al régimen subsidiado. La frecuencia más alta, dentro de las conductas investigadas, se refiere a las relacionadas con la votación por un candidato, que son conocidas por el $5 \%$ de las familias.

Se trata de fenómenos que afectan la calidad y sesgan los procesos de selección y afiliación de beneficiarios, tanto por la influencia de prácticas clientelistas como por otro tipo de intereses (económicos, familiares, etc.).

Desarrollo institucional

Algunos indicadores expresan limitaciones y deficiencias en el grado de desarrollo institucional del Sisben como programa en los municipios:

- La estabilidad en el cargo del administrador del Sisben, como expresión de la continuidad en trabajos de administración del Sisben, muestra una alta movilidad. Entre 1998 y junio de 2000 en 52,4 \% de los municipios hubo más de un administrador y en 30,3 \% más de dos.

- En $60 \%$ de los municipios el administrador se dedica en forma exclusiva a las actividades propias del Sisben, sin compartir otras funciones. En los municipios medianos el $79 \%$ tiene esta dedicación y en los pequeños el 45 \%. 
- El nivel educativo del administrador con mayor frecuencia es el de bachillerato: 38,3 \%. El $20,6 \%$ ha completado estudios universitarios y el 14,6 \% ha cursado estudios en este nivel sin completarlos. Un 4,3 \% tiene especialización y $21,7 \%$ ha hecho estudios técnicos. En los municipios grandes $32 \%$ ha completado estudios universitarios, $23,3 \%$ tiene postgrado o especialización y 40,6 \% estudios técnicos. Entre los pequeños 46,5 \% tiene estudios de bachillerato, 16,6 \% estudios universitarios incompletos e igual proporción estudios técnicos.

- El 23 \% de los administradores del Sisben no ha recibido capacitación especializada para las funciones de este cargo.

- Una expresión del grado de institucionalización del Sisben es la existencia de un grupo de trabajo para su administración. En el 65,3 \% de los municipios se cuenta con él. En $40 \%$ de los municipios pequeños no se ha implementado, esto mismo sucede en el 19,3\% de los medianos y el $4,2 \%$ de los grandes.

- En el 73,3 \% de los municipios no están constituidos los comités técnicos del Sisben, contemplados en las orientaciones técnicas que se dieron desde el inicio del programa.

Los resultados de la focalización

Errores de inclusión observados. Las deficiencias de cobertura, calidad y actualización en la información, y las limitaciones en la aplicación y administración del Sisben, en muchos municipios, guarda correspondencia con la pérdida de precisión en la asignación de subsidios a los pobres.

Hacia el año 2000 alrededor del $80 \%$ de los afiliados al régimen subsidiado habían sido seleccionados utilizando el Sisben (7). La creciente aplicación de este instrumento en los municipios contrasta, sin embargo, con un deterioro creciente en los niveles de precisión en la focalización del régimen subsidiado. Entre 1997 y 2000 la proporción de no pobres afiliados a este régimen aumentó de $27 \%$ a $39 \%$, según información de las encuestas nacionales de hogares (Tabla 3). Frente a un error "teórico" tipo 1 de 14,9 \%, en la utilización de los niveles Sisben 1 y 2 para incluir a los no pobres, el error de inclusión observado es de más del doble en 2000, al estar afiliadas 2780000 personas no pobres en el régimen subsidiado. La subsistencia de mecanismos distintos al Sisben para hacer la selección de beneficiarios, y el mantenimiento de la afiliación de los afiliados por esos medios no permite, sin embargo, atribuir este resultado en forma exclusiva al Sisben.

De otra parte, las distorsiones que afectan la selección de beneficiarios al régimen subsidiado tienen también origen en factores objetivos de la compleja situación del país. Mientras las políticas de flexibilización laboral se imponen, aumenta la informalidad en el empleo y las tasas de desempleo alcanzan máximos históricos cercanos al $20 \%$, los mecanismos de identificación y selección mantienen rigideces y se realizan a través de mecanismos, que no corresponden con la situación inestable y cambiante de los hogares. 
Si bien desde el punto de vista de la metodología del Sisben y los criterios definidos para identificar los beneficiarios a través suyo, la deficiencia principal es el error de excluir a una proporción importante de pobres, en la aplicación de los distintos mecanismos de selección de afiliados se encuentra una proporción importante de no pobres afiliados.

La dinámica del proceso, en un contexto donde aumenta el número de pobres, hay un estancamiento en la cobertura de la seguridad social en salud y un incremento en los errores de inclusión, ha conducido a que mientras la tasa de afiliación al régimen subsidiado de los pobres disminuya entre 1997 y 2000, de $27 \%$ a 20,3 \%, la de los no pobres se incremente de 9,2 \% a 13,4 $\%$.

Los avances en la afiliación a la seguridad social en salud

Las fallas en la focalización han afectado los logros en el aseguramiento de los sectores pobres. No obstante, es preciso encuadrar estos resultados dentro del conjunto del proceso de expansión de la seguridad social en salud y de la aplicación de la reforma instaurada por la Ley 100.

Tabla 3. Población por condición de afiliación al sistema de seguridad social en salud, según situación de pobreza. Total Nacional 1997 y 2000

\begin{tabular}{|c|c|c|c|c|c|c|}
\hline \multirow{2}{*}{$\begin{array}{c}\text { Condición de } \\
\text { Afiliación a la } \\
\text { seguridad social en } \\
\text { salud }\end{array}$} & \multicolumn{3}{|c|}{1997} & \multicolumn{3}{|c|}{2000} \\
\hline & Total & No pobres & Pobres & Total & No pobres & Pobres \\
\hline Total & 39842424 & 20887141 & 18955283 & 42022021 & 20746147 & 21276674 \\
\hline AFILIADOS & 22784218 & 13788202 & 8996016 & 21991748 & 12479101 & 9512647 \\
\hline Régimen Contributivo & 15750872 & 11864515 & 3886357 & 14874435 & 9696486 & 5177949 \\
\hline Régimen Subsidiado & 7033346 & 1923687 & 5109659 & 7089723 & 2777940 & 4311783 \\
\hline Sin información & & & & 27590 & 4675 & 22915 \\
\hline NO AFILIADOS & 17058206 & 7098939 & 9959267 & 19842570 & 8175111 & 11667459 \\
\hline Sin información & & & & 188503 & 91935 & 96568 \\
\hline Porcentajes verticales & Total & No pobres & Pobres & Total & No pobres & Pobres \\
\hline Total & 100,0 & 100,0 & 100,0 & 100,0 & 100,0 & 100,0 \\
\hline AFILIADOS & 57,2 & 66,0 & 47,5 & 52,3 & 60,2 & 44,7 \\
\hline Régimen Contributivo & 39,5 & 56,8 & 20,5 & 35,4 & 46,7 & 24,3 \\
\hline Régimen subsidiado & 17,7 & 9,2 & 27,0 & 16,9 & 13,4 & 20,3 \\
\hline Sin información & & & & 0,1 & 0,0 & 0,1 \\
\hline NO AFILIADOS & 42,8 & 34,0 & 52,5 & 47,2 & 39,4 & 54,8 \\
\hline Sin información & & & & 0,4 & 0,4 & 0,5 \\
\hline Porcentajes horizontales & Total & No pobres & Pobres & Total & No pobres & Pobres \\
\hline Total & 100,0 & 52,4 & 47,6 & 100,0 & 49,4 & 50,6 \\
\hline AFILIADOS & 100,0 & 60,5 & 39,5 & 100,0 & 56,7 & 43,3 \\
\hline Régimen Contributivo & 100,0 & 75,3 & 24,7 & 100,0 & 65,2 & 34,8 \\
\hline Régimen subsidiado & 100,0 & 27,4 & 72,6 & 100,0 & 39,2 & 60,8 \\
\hline Sin información & & & & 100,0 & 16,9 & 83,1 \\
\hline NO AFILIADOS & 100,0 & 41,6 & 58,4 & 100,0 & 41,2 & 58,8 \\
\hline Sin información & & & & 100,0 & 48,8 & 51,2 \\
\hline
\end{tabular}

Fuente: Procesamiento del CID de la Encuesta Nacional de Calidad de Vida de 1997 (archivos Misión Social) y de la etapa 107 de la Encuesta Nacional de Hogares-DANE. La estimación de la pobreza para el año 2000 se hizo sin ajuste de los ingresos por sub-declaración utilizando los valores de la línea de pobreza del DANE.

A mediados de los años ochenta Colombia tenía una baja tasa de afiliación de la población a la seguridad social en salud, respecto a la mayor parte de los países de América Latina. Hacia 1985, el conjunto de afiliados en el país no llegaba al 15 \% mientras que el promedio de la región era de 
58\%, el de Costa Rica y Brasil de $85 \%$, el de Chile y Argentina de $75 \%$, el de México de 60 \% y el de Venezuela de 50 \% (10). La afiliación a la seguridad social en salud era hasta ese momento un privilegio que abarcaba a los trabajadores formales, una fracción de sus familiares y a quienes podían costear un seguro prepagado.

Con la Ley 100 las tasas de afiliación a la seguridad social en salud aumentaron vertiginosamente. Entre 1993 y 2000, en el nivel nacional, se multiplicaron por 2,2 pasando de 23,8 a 52,2 \%. Durante este lapso aumenta la afiliación por pago de contribuciones que alcanza el 35,5 \% de la población, y la del régimen subsidiado llega al 16,7 \% (Tabla 4).

En el segmento de pobreza extrema (indigencia) las tasas globales de afiliación aumentaron 7 veces, de 5,2 a 36,6 \%, dentro de los pobres no indigentes 3 veces, de 16,5 a 48,9 \%, y dentro de los no pobres 1,7 veces, de 34,7 a 60 \%. En las áreas rurales la proporción de afiliados ascendió 5,7 veces y en las urbanas 1,8 veces. Para el conjunto de trabajadores se incrementaron en 1,8 veces, para los desempleados en 2,6, para los estudiantes en 2,1, 3 veces para las personas dedicadas a oficios del hogar, 4 veces las de los trabajadores independientes, patronos y familiares sin remuneración, y 5,2 veces las de los empleados domésticos.

Tabla 4. Tasas de afiliación a la seguridad social en salud por condición

\begin{tabular}{|c|c|c|c|c|c|c|c|}
\hline $\begin{array}{c}\text { Condición de afiliación } \\
\text { de pobreza y zona }\end{array}$ & 1993 & 1994 & 1997 & 2000 & $\begin{array}{l}1993 \\
2000\end{array}$ & $\begin{array}{l}1993 \\
1997\end{array}$ & $\begin{array}{l}1997 \\
2000\end{array}$ \\
\hline & \multicolumn{4}{|c|}{ Valores } & \multicolumn{3}{|c|}{ Porcentajes de variación } \\
\hline \multicolumn{8}{|c|}{ Tasas de afiliación } \\
\hline Total & 23,8 & 26,6 & 57,2 & 52,2 & 119,0 & 139,8 & $-8,7$ \\
\hline Régimen Subsidiado & -- & -- & 17,7 & 16,7 & -- & -- & 5,5 \\
\hline Régimen Contributivo & 23,8 & 26,6 & 39,5 & 49,1 & 65,8 & $-10,1$ & \\
\hline Población pobre no indigente & 16,5 & 19,0 & 50,8 & 48,9 & 195,8 & 207,4 & $-3,8$ \\
\hline Población pobre indigente & 5,2 & 6,4 & 41,9 & 36,6 & 603,5 & 706,9 & $-12,8$ \\
\hline Población no pobre & 34,7 & 38,4 & 66,0 & 60,0 & 73,0 & 90,4 & $-9,1$ \\
\hline Población urbana & 31,0 & 33,0 & 60,9 & 56,8 & 83,5 & 96,7 & $-6,7$ \\
\hline Población rural & 7,1 & 7,1 & 47,5 & 40,4 & 471,1 & 572,1 & $-15,0$ \\
\hline
\end{tabular}

En este proceso se identifican dos fases. Durante la primera, comprendida entre 1993 y 1997, se observa un rápido y generalizado crecimiento de la afiliación. En la segunda, que abarca los años finales de la década pasada, la tendencia se vio revertida, en un contexto que guarda correspondencia con la crisis económica. Durante ella, la proporción de afiliados inicia una trayectoria descendente. Las tasas de afiliación al régimen subsidiado pasaron de 17,7 \% a 16,7 \% y las del contributivo de 39,5 \% a 35,5\%. Y como resultado las tasas generales de afiliación a la seguridad social en salud, de 57,2 \% en 1997, llegaron a 52,2 \% en el 2000.

El cambio de tendencia, afectó en especial a los sectores pobres. Frente a un decrecimiento general de 8,7 \% en las tasas de afiliación, disminuyeron más rápidamente las de los “indigentes”, $12,8 \%$ y las áreas rurales, $15 \%$. En las zonas urbanas el régimen subsidiado continuó 
incrementándose, aunque a un ritmo más lento que en los años precedentes, y la proporción de afiliados al régimen contributivo bajó de 49,3 a 44,1 \%. Y en las rurales decrece la proporción de afiliados en los dos regímenes y especialmente en el subsidiado que pasa de 33 a $27 \%$.

A pesar de los retrocesos en la cobertura de afiliación y la pérdida de precisión en la focalización, los resultados siguen siendo apreciables. La dinámica del proceso llevó el aseguramiento en salud a una fracción de los sectores sociales marginados históricamente de este beneficio. Y además la asignación de subsidios produjo un progresivo efecto redistributivo del ingreso. Según Sánchez (11) entre 1993 y 1997 el incremento tanto en la afiliación como en el acceso a los servicios de salud de la población pobre, llevó a aumentar el grado de focalización del gasto en salud en los pobres y a producir un efecto progresivo en la distribución del ingreso. En 1997 más del 66 \% de los subsidios del régimen subsidiado estuvieron dirigidos al $40 \%$ más pobre de la población, mientras que el quintil 5 recibió únicamente el $2 \%$ de estos subsidios. Tales han sido los logros más importantes de las reformas instauradas por la Ley 100 y, quizás, en el conjunto de las políticas sociales en Colombia durante la pasada década.

Este recorrido muestra que, no obstante las deficiencias en los procesos de selección de afiliados al régimen subsidiado, hubo un avance considerable en la afiliación de los pobres a la seguridad social en salud. La situación se explica porque en el momento inicial la discriminación en el aseguramiento era de tal magnitud (5,2 \% de afiliados en los indigentes y 16,5 \% en los pobres no indigentes), que con cualquier procedimiento de selección que disminuyera las barreras de acceso y controlara la asignación de subsidios para no pobres, se podrían lograr aumentos rápidos y considerables en la afiliación de los pobres. Para tal efecto no se requería de un instrumento técnico de gran precisión, ni controles estrictos en su aplicación, y los errores de exclusión podían ser grandes, ya que los cupos disponibles en el régimen subsidiado sólo han alcanzado para una tercera parte de los pobres, y para el $30 \%$ de los clasificados en los niveles 1 y 2 del Sisben.

Las características técnicas del índice Sisben para disminuir los errores de inclusión de los no pobres, a pesar de sus limitaciones técnicas y los problemas en su aplicación, le dieron ventajas prácticas, en este contexto, frente a otras alternativas. Y su aplicación permitió un crecimiento acelerado de la afiliación en los sectores pobres, con los recursos destinados al régimen subsidiado, a pesar de sus limitaciones técnicas y los problemas en su aplicación.

Inequidades en la afiliación y nuevas desigualdades en el acceso a los servicios de salud

La reducción de las distancias en el aseguramiento de salud, entre distintas categorías sociales, no ha suprimido las desigualdades sociales, que siguen siendo pronunciadas. Al interior de los estratos 1, 2 y 3 de las ciudades, investigados por la encuesta de la Universidad Nacional en el 2000, frente a una tasa promedio de afiliación de 45,2 \%, sólo el $30 \%$ de la población de los niveles 1 y 2 del Sisben cuenta con aseguramiento, mientras que lo tiene el $65 \%$ de la clasificada en el nivel 4 . Dentro de los grupos con las peores oportunidades de afiliación se encuentran los niños menores de 1 año con 31,5 \% de afiliados, en el total de la población, y con $21 \%$ en los niveles 1 y 2 del 
Sisben; los migrantes recientes (menos de un año en la ciudad) con 30 \%; los desempleados con 23 $\%$, los trabajadores independientes y domésticos, y los inválidos con $33 \%$.

Tomando como patrón de referencia la distribución general de la población analizada, por edad y género, y comparándola con la de los afiliados del régimen subsidiado, se tiene una medida del grado en que los grupos demográficos se encuentran representados en la afiliación de este régimen, y una percepción de la forma como opera la selección adversa y de la que favorece a determinados grupos. Con este procedimiento, se observa que los menores de 1 año se encuentran subrepresentados en $14 \%$, es decir, que al interior de este régimen de aseguramiento, su participación es inferior en ese porcentaje a la del grupo dentro del total de la población. Para los niños entre 1 y 5 años, también existe sub-representación, aunque de menor magnitud: 0,8 \%. El grupo de 65 y más años tiene sobre rreprentación de $41 \%$ y las mujeres en edad fértil están subrepresentadas en cerca al $9 \%$.

De esta forma, dentro de los sectores vulnerables desde el punto de vista demográfico, sólo el de la tercera edad recibe un tratamiento especial. Y se evidencia que las normas y procedimientos orientados a dar preferencia en la afiliación al régimen subsidiado a los niños e incapacitados no han tenido el efecto esperado en este universo de análisis. Igual sucede con las mujeres en edad reproductiva que tienen menores probabilidades de estar cubiertas por el aseguramiento subsidiado de salud, a los del promedio de la población, aunque su condición merecería un trato prioritario.

La sub-representación de estos grupos es expresión de una selección adversa, es decir que da prelación a los grupos cuyo aseguramiento requiere menores costos, en contra de sectores vulnerables, cuyo aseguramiento individual es más caro. No se trata necesariamente de un resultado deliberado, que sea atribuible totalmente a las entidades que hacen la selección y prestan el aseguramiento. A este efecto contribuyen diferentes factores relacionados con la forma como opera el modelo. Uno de ellos es el lento aumento de la afiliación subsidiada en los últimos años, que deja con menores oportunidades a las iniciales a las nuevas familias.

Además, los avances parciales de la afiliación a la seguridad social en salud logrados a través de la aplicación de la reforma instaurada por la Ley 100 ha acentuado dos tipos de desigualdades en el acceso a los servicios de salud. De una parte, entre los sectores medios sin afiliación, que han visto deterioradas sus condiciones de atención a la salud, y el conjunto de afiliados. Y, de otra, al interior de los pobres que se ven segmentados entre quienes tienen afiliación, con mayores oportunidades para el mejoramiento de su salud y más bajos costos para hacerlo, y los no afiliados. En la situación de recesión económica esta doble escisión se ha expresado en la profundización de las desigualdades para el acceso a los servicios de salud.

Entre 1994 y 2000, no se observa un cambio significativo en la proporción de personas que se sintieron enfermas en los últimos 30 días y fueron atendidas por profesionales de la salud, en el conjunto de la población urbana de los estratos 1 a 3. De 77,1 \% de atendidos en 1994 se pasa a $77,6 \%$ en 2000. Dentro de los afiliados, la proporción aumenta de 83,5 \% a $89 \%$, como consecuencia de una mayor atención a los afiliados de los dos regímenes a partir de 1997. Entre este 
año y 2000 la atención médica a los enfermos del subsidiado ascendió de 71,7 \% a 82,5 \%, y la del contributivo de $85,9 \%$ a $91,7 \%$. En contraste, el porcentaje de atendidos para los enfermos sin afiliación cae de 73,5 \%, en 1994, a 65,7 \%, en 2000.

La instauración del régimen subsidiado ha creado una red de protección para una parte de los sectores sociales desfavorecidos que han mejorado sus condiciones de acceso a los servicios. La caída en la afiliación al régimen contributivo en estos sectores urbanos como producto de la crisis económica, con una pérdida en las condiciones de atención para los no afiliados, ha llevado, por el contrario, a que una capa intermedia que puede estar abarcando una tercera parte de la población de los estratos 1 a 3 de las ciudades tenga, en su conjunto, peores condiciones de acceso a los servicios para tratar la enfermedad que la población con NBI antes de la aplicación de la reforma implantada por la Ley 100. El 73 \% de los enfermos, dentro de este sector, que no asistieron a consulta de personal de la salud, informan como motivo la falta de dinero.

La otra notable diferenciación que introduce la aplicación del modelo se ubica dentro de los grupos con nivel de vida inferior (niveles 1 y 2 del Sisben). A su interior, los no afiliados -el 70 \%reciben atención de personal de la salud en el $64 \%$ de las situaciones de enfermedad, mientras que los afiliados al régimen subsidiado la tienen en el $80 \%$ de los casos. Y en el $65 \%$ de tales circunstancias el motivo para no concurrir a los servicios es la falta de recursos económicos, mientras que para los afiliados al régimen subsidiado esta razón afecta sólo al $27 \%$ de los no atendidos. La brecha de pobreza, como carencia de capacidades básicas, disminuye para un segmento poblacional, pero se incrementa la desigualdad al interior de los pobres.

\section{Distorsiones de información y estigma social}

En el curso de la investigación realizada por el CID de la Universidad Nacional, "fuera de registro" y en forma anecdótica, se encontraron testimonios de esa "creatividad" para acceder a privilegios en forma fraudulenta por parte de ciertos sectores de la población: desde la mentira directa a las preguntas del formulario del Sisben que no pueden ser comprobadas y que más inciden en el índice, y el ocultamiento de equipamientos como el televisor o la nevera, hasta la separación temporal de cónyuges, para que la mujer pueda declararse como jefa de familia, el "préstamo" de niños, para hacerlos aparecer como miembros del núcleo familiar, y el alquiler de lugares precarios de habitación para que se aplique la encuesta. En determinados lugares se detectó que la exigencia de algunos habitantes de que se les avisara sobre el momento de aplicación de las encuestas, buscaba ganar tiempo para adecuar la composición del hogar y las condiciones de las viviendas, y así obtener puntajes inferiores. Y, en otros, cuando llegaban los encuestadores se presentaban voceadores callejeros que gritaban: “escondan el televisor que viene el Sisben”.

Estas conductas son aceptadas e incluso celebradas en algunos contextos, aunque, no pueden generalizarse y seguramente sólo tiene lugar en una minoría de la población. Junto a los testimonios que las describen se encuentran otros sobre comunidades que ejercen un autocontrol para evitar que los subsidios sean asignados a quienes tienen mayores recursos, y sobre los casos de familias que 
renuncian voluntariamente a ser subsidiadas, aunque cumplan los requisitos para ello, porque hay personas más necesitadas que ellas.

Las distorsiones de información provenientes de la población para la identificación de beneficiarios del régimen subsidiado son respuestas ante cambios de percepción sobre el aseguramiento a la salud, y ante una desconfianza y falta de legitimidad de los instrumentos a través de los cuales se lleva a cabo. La decisión del DNP de mantener en secreto los procedimientos prácticos para el cálculo de los puntajes y los detalles técnicos del diseño del "nuevo" índice, de forma que pueda ser evaluado públicamente y en forma trasparente, refuerza estas tendencias.

Con la puesta en operación de la Ley 100, en una fase de deterioro generalizado de los niveles de vida durante los años finales de la década pasada, la población de los sectores populares ha cambiado su escepticismo inicial frente a la afiliación a la seguridad social en salud y coloca sus expectativas en la posibilidad de lograrlo a través de un subsidio. El relieve que adquirió el tema “Sisben" en las elecciones presidenciales de 2002, y en las de alcaldes de 2003, a diferencia de las anteriores, corresponde con un cambio en las valoraciones sobre los beneficios del aseguramiento de salud y en las expectativas para adquirir un cupo en el régimen subsidiado, que chocan con las posibilidades de lograrlas frente a la baja dinámica de crecimiento de la afiliación en los últimos años.

En esas circunstancias hay segmentos apreciables de la población que desconfían de los instrumentos técnicos del Sisben y de la forma como se aplican. Una expresión de las percepciones a este respecto se encuentra en que el 32\% de la población "Sisbenizada" de los estratos 1 a 3 de las principales ciudades pertenece a núcleos familiares que están en desacuerdo con el puntaje que se les ha asignado. Dentro de ellos, el $35 \%$ considera que la encuesta está desactualizada y no refleja su situación actual, el 22 \% que estuvo mal aplicada, y el 38 \% que a través de encuestas de este tipo no se captan adecuadamente las condiciones importantes de vida de las familias.

Otra manifestación del fenómeno se encuentra en las apreciaciones de las administraciones municipales sobre el Sisben. En cerca del 60 \% de los municipios investigados por la Universidad Nacional en 2000, contestaron en forma negativa a la pregunta sobre si el Sisben selecciona adecuadamente a las personas que merecen estar en el régimen subsidiado. Y una proporción semejante de secretarías departamentales de salud se pronunció en el mismo sentido.

En algunos casos de indigencia manifiesta de las familias o de víctimas de enfermedades de alto costo que viven en barrios de sectores medios y son pobres desde el punto de vista de los ingresos, el índice Sisben se convierte en obstáculo evidente para dar atención a los más necesitados. En estas oportunidades se requiere el traslado a suburbios con peores condiciones de vida, o el recurso al mecanismo constitucional de la tutela por violación de los derechos fundamentales a la vida y a la igualdad.

En estas circunstancias, existe la percepción de que en algunos contextos culturales colombianos las expresiones y efectos del estigma social que podría generar la aplicación de los mecanismos de 
selección de destinatarios del régimen subsidiado tienen poco efecto negativo. En ciertos medios su ocultamiento se debe a que dentro de la mentalidad del "vivo", el lograr un subsidio para los pobres, en forma engañosa, puede ser bien visto. Es expresión de ese modo de organización social que ha sido llamada el almendrón (12). En otros, el estar clasificado en los niveles 1 y 2 del Sisben o afiliado al régimen subsidiado de salud, aún en el marco de las normas, no son necesariamente señales de pobreza, y también por eso el estigma de ser pobre y la afectación de la autoestima pueden quedar desdibujados.

De otra parte, no hay registros confiables sobre la forma como operan otros incentivos promovidos por la selección de beneficiarios de subsidios a través de la estimación indirecta de la capacidad de pago. Dadas las variables que se utilizan para hacerlo, puede inducir conductas en torno a los modos de vida de la población y los comportamientos económicos. Quedar clasificado y mantener la afiliación es cumplir los requisitos para no exceder un puntaje, de acuerdo a una metodología que es de público conocimiento: los servicios públicos, las condiciones de la vivienda y el entorno barrial, los equipamientos domésticos, la educación, el empleo, los ingresos, el tipo de familia e incluso el número de hijos. En todo caso, las valoraciones sociales se ven afectadas y algunos sectores de la población expresan su insatisfacción porque los esfuerzos que han hecho para mejorar su vivienda y tener mejor educación les dan desventajas frente a vecinos, que han tenido iguales oportunidades y que son premiados, sin haber tenido la misma persistencia para progresar, con sus modestos recursos, en sus condiciones de vida.

\section{CONCLUSIONES}

El proceso de selección de beneficiarios del régimen subsidiado es una pieza clave del modelo institucional establecido por la Ley 100, y la forma como se lleve a cabo condiciona el logro de los objetivos de largo plazo del sistema de seguridad social en salud en términos de cobertura universal e integral y unificación efectiva de derechos para toda la población.

Los avances en el aseguramiento de la salud no han llevado a suprimir las grandes desigualdades y carencias de capacidades para amplios sectores de la población, que subsisten en este campo. En la perspectiva de una progresiva y rápida afiliación, la situación de crisis económica ha impuesto un proceso más prolongado, y la experiencia ha planteado dificultades prácticas no previstas. Estas circunstancias han llevado a que las tasas de afiliación hayan tomado una trayectoria decreciente y hacen urgente una revisión de los criterios prácticos para determinar la población destinataria del régimen subsidiado en la fase de transición fijada por la Ley 100 y para la asignación de subsidios.

Los elementos de evaluación del Sisben conducen a apreciar las grandes dificultades técnicas para lograr un mecanismo de identificación de beneficiarios de subsidiados para el aseguramiento de salud, que permita razonablemente incluir a las poblaciones más pobres, de acuerdo a su capacidad de pago, y a excluir a quienes la tienen. El índice Sisben no logra captar adecuadamente una alta proporción de las situaciones particulares de privación de capacidades para el disfrute de la salud y su aplicación para la selección de beneficiarios, bajo la perspectiva de los ingresos, conduce a errores de exclusión demasiado elevados. 
Existen, además, notables fallas en la calidad, cobertura y actualización de la información del Sisben, como programa de los municipios, y en los procesos de su implementación. Después de las primeras encuestas masivas realizadas requeridas para recibir las transferencias nacionales destinadas al régimen subsidiado, la asignación de subsidios ha llevado, en la gran mayoría de los casos, a otorgar un privilegio que en la práctica se ha convertido en permanente. El problema prioritario ha sido cómo incluir nuevos afiliados y poca atención se ha prestado a evaluar los subsidios ya concedidos, con criterios generales de equidad y eficiencia. Bajo esta perspectiva el Sisben sólo fue útil para asignar los relativamente escasos nuevos cupos del régimen subsidiado, o para determinar las tarifas que debían pagar los “vinculados” en los hospitales, lo que podía hacerse, en la mayor parte de municipios, sin una actualización permanente de la información y sin aumentar la cobertura.

Con las altas proporciones de no afiliados que cumplen con las condiciones para ingresar al régimen subsidiado se torna indefinida la población destinataria. Esta situación, agravada por los problemas de las finanzas municipales, condujo a que, en muchos casos, las encuestas Sisben se mantuvieran desactualizadas, después de su aplicación generalizada en 1995 y 1996, y no se haya logrado una cobertura satisfactoria. Y fue propicia para dar cabida al juego de intereses de sectores políticos o grupos de presión que, en alguna medida, han promovido su interés particular y no el de la colectividad, en el manejo de los recursos del sistema de seguridad social en salud. A tal efecto coadyuvó igualmente la falta de consolidación de mecanismos de monitoreo y control, y de participación ciudadana en torno a la selección y afiliación de beneficiarios en los municipios.

El resultado ha sido una tendencia al deterioro progresivo de los niveles de focalización de los subsidios en los pobres, a pesar de que se ha generalizado el uso del Sisben.

Es evidente que la solución a la compleja problemática descrita pasa por mejorar la calidad técnica de los instrumentos técnicos y en crear mecanismos organizativos e institucionales adecuados para su aplicación. En este sentido se viene adelantando un trabajo técnico por parte del Departamento Nacional de Planeación que ha rediseñado el índice Sisben, cambiando algunas de sus variables y modificando sus ponderaciones, y a comienzos de 2003 fue puesto en marcha un amplio programa para el relanzamiento generalizado del Sisben en los municipios. Su desarrollo seguramente tendrá un efecto positivo en lo inmediato, pero es sólo parte provisional de una salida a largo plazo.

El programa del "nuevo" Sisben se puede esperar una actualización de la información y una mejora en la calidad de la misma. Eso es positivo y era necesario desde hacía mucho tiempo. No obstante, en los aspectos de ampliación de cobertura puede mantener problemas anteriores ya que se da prioridad a zonas donde de acuerdo al "viejo"Sisben predominaban los segmentos pobres, sin tomar en cuenta criterios que contrarresten sus fallas. De otra parte, es un programa que no considera acciones sistemáticas para que los mecanismos institucionales y los recursos de los municipios puedan operar de forma permanente para la administración del Sisben (asistencia técnica, capacitación, fortalecimiento institucional, mecanismos de vigilancia desde las comunidades). 
Y, por último, no se plantea dentro del horizonte de buscar mejores soluciones a largo plazo para llevar a cabo la focalización de subsidios de salud y para proveer de instrumentos al Sistema de Seguridad Social en Salud, hacia la unificación de los servicios de los dos regímenes y la integración de los mecanismos para fijar tarifas y subsidios parciales.

En relación con el nuevo índice Sisben, por el momento no parece factible, que se logre un resultado considerablemente mejor para evitar los errores de exclusión e inclusión a través de la adición o supresión de variables o de calibrar las ponderaciones del "viejo". Puede haber avances, y hay que intentarlos, pero sin la ilusión de que con ellos se obtendrá un cambio substancial de los niveles de precisión para identificar a los pobres. Aunque la metodología detallada del "nuevo" Sisben se mantiene oculta y se desconoce cuáles son sus errores de inclusión y de exclusión, no hay razones que lleven a pensar que con el cambio de algunas variables y de las ponderaciones se logren resultados técnicos substancialmente mejores que con el anterior índice.

La actitud de mantener en secreto los detalles de las metodologías del nuevo índice es dudosa desde el punto de vista de nuestro marco jurídico; y también en su efectividad. Reafirma la desconfianza existente y quita legitimidad al instrumento, bajo la suposición de que la población es tramposa y actúa sólo en su propio provecho: simplemente hay que llevarle instrumentos hechos, para que no manipule la información. Expresa una actitud poco democrática, que riñe con la transparencia en los asuntos públicos. No se trata de un simple asunto técnico, es un asunto político. Los criterios y procedimientos técnicos aplican e interpretan normas y valores, que en este caso se refieren a quiénes son los merecedores de subsidios. Se trata de un tema cuyo conocimiento y discusión merecen ser propiciados.

La universalización de la afiliación tiene como ventaja que es un medio a través del cual se pueden contrarrestar las diferencias sociales para que cada cual reciba los servicios de salud en correspondencia con sus necesidades, y haga sus aportes de acuerdo con sus capacidades. Pero el proceso para lograrlo es prolongado y, al no haber mecanismos de compensación adecuados para los no afiliados, se generan inequidades como las que han sido comentadas.

Hacia el logro de la imagen objetivo planteada por la Ley 100 se requiere, durante la fase de transición y en la perspectiva de la unificación de los dos regímenes existentes, que el sistema de identificación de beneficiarios adoptado opere en la búsqueda de dos objetivos. El primero el reconocimiento de la población con mayor vulnerabilidad ante los riesgos de la salud, a quienes se debería dar prioridad, que no están recibiendo, en la afiliación. Y, en segundo lugar, el establecimiento paulatino de una clasificación de la población que permita diferenciar los más pobres, para asignación de subsidios totales, el segmento al que se le otorgarían subsidios parciales y los estratos dentro de quienes tengan capacidad de pago, para la asignación de tarifas. El mantenimiento de una separación en los registros de afiliación entre los dos regímenes sólo lleva a perpetuar la segmentación existente.

Un horizonte como éste plantea directrices que lleven a conciliar los criterios de asignación de subsidios teniendo en cuenta la privación de capacidades en el campo específico de la salud, con el 
de falta de capacidad de pago. Sobre el primer criterio el mismo sistema de salud tiene ventajas para aportar la información necesaria. Y, en relación con el segundo, una vez logrado un nivel significativo de afiliación, el mismo sistema puede ir creando mecanismos que vayan proveyendo los datos requeridos, a través de un registro único de afiliados y personas atendidas por la red pública de salud, no sólo para identificar los más pobres, sino también los grupos a los que se asignen subsidios parciales y los que correspondan con distintos niveles de tarifas. La perspectiva es irlos consolidando, y utilizar el Sisben y otras fuentes de información con este propósito.

Adicionalmente, se requiere crear mecanismos complementarios que corrijan los errores de los instrumentos técnicos para la selección de beneficiarios, como el Sisben, y de su aplicación, especialmente los que excluyen de los subsidios a familias en pobreza extrema y a sectores vulnerables. Dentro de ellos es preciso promover análisis de profundización sobre las condiciones de las familias excluidas, que permitan corregir los resultados de los sistemas masivos de identificación. Y también la instauración de formas de participación desde la sociedad civil, que conceptúen sobre los casos particulares de vulnerabilidad y pobreza, excluidos de la afiliación subsidiada por esos sistemas, tomando en cuenta las condiciones particulares de los hogares (“tribunales de equidad”).

Finalmente, es preciso igualmente investigar sobre la forma como operan los incentivos promovidos por la forma de asignación de subsidios, en los comportamientos individuales y en los valores e instituciones de la sociedad. Sobre esta base podrán afrontarse en mejor forma los riesgos que implica tomar en cuenta la capacidad de pago para otorgarlos en campos como el de la salud

\section{REFERENCIAS}

1. Sen A. Libertad y Desarrollo, 2000, Editorial Planeta, Bogotá

2. Sen A. The Political Economy of Targeting. In: Van de Walle, Dominique y Nead, Kimberly (ed.); 1995.

3. Castaño E, Moreno H. Metodología estadística del modelo de ponderaciones del Sistema de Selección de Beneficiarios de Programas Sociales (Sisben), DNP, Misión Social, Bogotá; 1994.

4. Castaño E. Metodología para la determinación de los puntos de corte del índice Sisben para la caracterización de la población pobre. DNP, Misión Social, Bogotá; 1995.

5. Vélez CE, Castaño E, Deutsch R. 1999. Una interpretación económica del sistema de focalización de programa sociales: el caso del Sisben en Colombia. Coyuntura Social No. 21, Bogotá; 1999, Noviembre.

6. Sarmiento A. Eficiencia horizontal y eficiencia vertical del sistema de selección de beneficiarios (Sisben). Coyuntura Social No.21, Bogotá; 1999, Noviembre.

7. Corporación Centro Regional de Población (CCRP), BDO Salud Age. Evaluación del proceso de focalización de subsidios en salud, en sus etapas de identificación, clasificación y selección de beneficiarios. Ministerio de Salud, Proyecto de Apoyo a la Reforma, Bogotá; 2000.

8. Universidad Nacional, Facultad de Ciencias Económicas, CID; Ministerio de Salud, Programa de Apoyo a la Reforma. La seguridad Social en la encrucijada, Tomos I, II y III, Bogotá; 2002.

9. El Tiempo, septiembre 8 de 2003 
10. Mesa Lago C. Financiamiento de la atención a la salud en América Latina y el Caribe con focalización en el Seguro Social. PNUD- Proyecto Regional para la superación de la pobreza; 1992.

11. Sánchez F, Núñez J. Descentralización, pobreza y acceso a los servicios sociales. ¿Quién se benefició del gasto público social? Coyuntura Social. 1999; 20.

12. Gómez BH (compilador) ¿Para dónde va Colombia?. Tercer Mundo, Colciencias, Bogotá; 1999. 